CLINICAL STUDY

\title{
Lower serum testosterone is independently associated with insulin resistance in non-diabetic older men: the Health In Men Study
}

\author{
Bu B Yeap ${ }^{1,2}$, S A Paul Chubb ${ }^{1,3}$, Zoë Hyde ${ }^{4}$, Konrad Jamrozik ${ }^{5}$, Graeme J Hankey ${ }^{1}$, Leon Flicker ${ }^{1,4}$ \\ and Paul E Norman ${ }^{6}$ \\ ${ }^{1}$ School of Medicine and Pharmacology, University of Western Australia, Perth, Western Australia 6009, Australia, ${ }^{2}$ Department of Endocrinology and \\ Diabetes and ${ }^{3}$ PathWest, Department of Biochemistry, Fremantle Hospital, Fremantle, Western Australia 6160, Australia, ${ }^{4}$ WA Centre for Health and \\ Ageing, University of Western Australia, Perth, Western Australia 6009, Australia, ${ }^{5}$ School of Population Health and Clinical Practice, University of \\ Adelaide, Adelaide, South Australia 5000, Australia and ${ }^{6}$ School of Surgery, University of Western Australia, Perth, Western Australia 6009, Australia
}

(Correspondence should be addressed to B B Yeap at School of Medicine and Pharmacology, University of Western Australia;

Email: byeap@cyllene.uwa.edu.au)

\begin{abstract}
Objective: Insulin resistance is associated with metabolic syndrome and type 2 diabetes, representing a risk factor for cardiovascular disease. This relationship may be modulated to some extent by agerelated changes in sex hormone status. We examined whether lower testosterone or sex hormonebinding globulin (SHBG) levels in older men are associated with insulin resistance independently of measures of central obesity.

Design: Cross-sectional analysis of 2470 community-dwelling non-diabetic men aged $\geq 70$ years.

Methods: Age, body mass index (BMI) and waist circumference were measured. Early morning sera were assayed for total testosterone, SHBG, LH and insulin levels. Free testosterone was calculated using mass action equations, and insulin resistance was assessed using a homeostatic model (HOMA2-IR). Results: Total testosterone, free testosterone and SHBG declined progressively across increasing quintiles of HOMA2-IR (all $P<0.001)$ and correlated inversely with log HOMA2-IR $(r=-0.27$, -0.14 and -0.24 respectively, all $P<0.001$ ). After adjusting for age, BMI, waist circumference, highdensity lipoprotein and triglyceride levels, total testosterone was independently associated with log HOMA2-IR $(\beta=0.05, P<0.001)$, while SHBG was not. Serum total testosterone $<8 \mathrm{nmol} / \mathrm{l}$ was associated with HOMA2-IR in the highest quintile (odds ratio (OR) 1.67, 95\% confidence interval (CI) $1.02-2.73$ ) as was total testosterone $\geq 8$ and $<15 \mathrm{nmol} / \mathrm{l}$ (OR 1.29, 95\% CI 1.03-1.63).

Conclusions: In older men, lower total testosterone is associated with insulin resistance independently of measures of central obesity. This association is seen with testosterone levels in the low to normal range. Further studies are needed to evaluate interventions that raise testosterone levels in men with reduced insulin sensitivity.
\end{abstract}

European Journal of Endocrinology $161591-598$

\section{Introduction}

Insulin resistance predisposes to metabolic syndrome and type 2 diabetes and may represent a risk factor for cardiovascular disease independently of these conditions $(1,2)$. However, the relationship between insulin resistance and cardiovascular disease may be confounded by sex hormone status. Castration of male rats is associated with insulin resistance, which is reversed with testosterone replacement (3). In men, low testosterone concentrations are associated with insulin resistance $(4,5)$ and the development of metabolic syndrome and type 2 diabetes (6-8), as well as with increased overall and cardiovascular disease mortality $(9,10)$. Further clarification of the interaction between testosterone and insulin resistance would contribute to the identification of men at greatest risk of cardiovascular disease.

In the circulation, testosterone is bound with high affinity to sex hormone-binding globulin (SHBG) and weakly to albumin, with a small fraction of unbound or free testosterone (11). At constant total testosterone, lower SHBG might be expected to be associated with higher free testosterone as the number of binding sites for testosterone would be less. However, lower SHBG has been associated with insulin resistance, increased risk of metabolic syndrome and possibly with increased mortality from cardiovascular disease $(8,12,13)$. During ageing, total and free testosterone levels decline, while SHBG levels increase (14-18). Therefore, even 
though total testosterone and SHBG concentrations are correlated $(4,16,17)$, levels of testosterone and SHBG diverge in older men. Thus, the relationships between testosterone, SHBG, insulin resistance and cardiovascular risk may alter during male ageing as sex hormone profiles mature. Clarifying the interaction between higher SHBG and lower total and free testosterone levels on insulin resistance could improve our understanding of hormonal associations with cardiovascular risk in men of different ages. Therefore, we evaluated the strength and independence of associations between testosterone and SHBG with insulin resistance in community-dwelling older men participating in the Health In Men Study (HIMS).

\section{Research design and methods}

\section{Study population}

The origins and characteristics of the HIMS have been described in depth elsewhere (19). Briefly, between October 2001 and August 2004, 4263 men resident in metropolitan Perth, Western Australia, participated in the study and provided a blood sample for analysis of biochemistry and hormone levels. Men were predominantly of Caucasian ethnicity. Stored sera were available for assay of hormone status in 4165 men. From these subjects, we excluded men taking testosterone replacement, non-fasting men, those being treated with androgen deprivation therapy, those with prostate cancer and those reporting diabetes or the use of glucose-lowering drugs ( $n=1663)$ leaving 2502 eligible subjects with fasting blood samples. Of these, no insulin result was available for 32 men, allowing 2470 men to be included in the final analysis. Height (in centimetres), weight (in kilograms), waist and hip circumference (in centimetres) and blood pressure were measured using standard procedures. The Human Research Ethics Committee of the University of Western Australia approved the study protocol. All study participants gave their written informed consent.

\section{Assessment of medical comorbidity}

We used the Charlson weighted index (20) to determine the presence of significant medical comorbidity in our sample. For this purpose, administrative medical information was obtained from the Western Australian Data Linkage System (21). Briefly, the system links together records from the Mental Health Information System, cancer registry, death registry and hospital morbidity data (which includes codes for multiple medical diagnoses for all admissions to private and public hospitals). Data were collected from 1990 to the time of blood sampling, providing a measure of recent comorbidity. Coding algorithms to define medical comorbidities followed the procedures described by
Quan et al. (22) and were calculated using Stagg's Charlson index Stata routine (StataCorp, College Station, TX, USA).

\section{Laboratory assays}

Fasting blood samples were collected between 0800 and $1030 \mathrm{~h}$. Serum was prepared immediately following phlebotomy and stored at $-80{ }^{\circ} \mathrm{C}$ until assayed. Biochemical and hormone assays were performed in the Biochemistry Department, PathWest, Royal Perth Hospital, Western Australia. Serum for total testosterone, SHBG and LH was analysed by chemiluminescent immunoassays on an Immulite 2000 analyzer (Diagnostic Products Corp. BioMediq, Doncaster, Australia). Between-day imprecision (coefficient of variation) for total testosterone was $11.2 \%$ at $7.2 \mathrm{nmol} / \mathrm{l}$ and $8.9 \%$ at $18 \mathrm{nmol} / \mathrm{l}$, for SHBG it was $6.7 \%$ at $5.2 \mathrm{nmol} / \mathrm{l}$ and $6.2 \%$ at $81 \mathrm{nmol} / \mathrm{l}$, and for $\mathrm{LH}$ it was $6.4 \%$ at $2.3 \mathrm{IU} / \mathrm{l}$ and $5.8 \%$ at $19 \mathrm{IU} / \mathrm{l}$. The working range of the testosterone assay was $0.7-55 \mathrm{nmol} / \mathrm{l}$; the sensitivities of the SHBG and LH assays were $2 \mathrm{nmol} / \mathrm{l}$ and $0.1 \mathrm{IU} / \mathrm{l}$ respectively. The established reference intervals for these assays are total testosterone $8-35 \mathrm{nmol} / \mathrm{l}$, SHBG 10-70 nmol/l and LH 1-8 IU/l. Fasting serum glucose, total and high-density lipoprotein (HDL) cholesterol and triglycerides (TG) were assayed using a Roche Hitachi 917 analyser (Roche Diagnostic $\mathrm{GmbH}$ ). Between-day imprecision for glucose was $2.9 \%$ at $4.8 \mathrm{mmol} / \mathrm{l}$ and $2.2 \%$ at $15.2 \mathrm{mmol} / \mathrm{l}$, for cholesterol it was $2.3 \%$ at $3.2 \mathrm{mmol} / \mathrm{l}$ and $2.1 \%$ at $6.7 \mathrm{mmol} / \mathrm{l}$, for HDL it was $2.4 \%$ at $0.8 \mathrm{mmol} / \mathrm{l}$ and $2.5 \%$ at $1.7 \mathrm{mmol} / \mathrm{l}$, and for TG it was $4.8 \%$ at $0.9 \mathrm{mmol} / \mathrm{l}$ and $2.4 \%$ at $2.0 \mathrm{mmol} / \mathrm{l}$. Fasting serum insulin was measured using an Elecsys 2010 analyser (Roche Diagnostics) with between-day imprecision of $4.6 \%$ at $11 \mathrm{mU} / \mathrm{l}$ and $3.3 \%$ at $33 \mathrm{mU} / \mathrm{l}$. The reference interval for this assay is $<12 \mathrm{mU} / \mathrm{l}$; to convert to pmol/l, we multiplied by 6.85 . Free testosterone, specifically the portion not bound to either SHBG or albumin, was calculated from total testosterone and SHBG using mass action equations as described by Vermeulen et al. (23). Insulin resistance was estimated from fasting glucose and insulin results by homeostasis model assessment, using the spreadsheet implementation of the HOMA2 calculator (HOMA2-IR, downloaded from www.dtu.ox.ac.uk/homa) (24).

\section{Statistical analysis}

Data were analysed with the statistical package Stata version 10.0 (StataCorp, 2007). As the distribution of HOMA2-IR was skewed to the right, we log transformed this variable for analysis. Trends across quintiles were assessed with Cuzick's non-parametric test for trend. Pearson's correlation coefficients were used to measure associations between continuous variables of hormone levels and insulin resistance (log HOMA2-IR). Multivariate linear regression was undertaken to explore 
hormonal associations with insulin resistance (log HOMA2-IR as a continuous variable) adjusting for potential confounders. Multivariate logistic regression was undertaken to examine associations of hormone levels with HOMA2-IR falling in the highest quintile of values. Covariates included age, body mass index (BMI), waist circumference, total testosterone, SHBG, HDL level and TG level. All tests were two-sided, and $P$ values $<0.05$ were considered statistically significant.

\section{Results}

\section{Distribution of HOMA2-IR values}

The frequency distribution of HOMA2-IR values in this cohort of 2470 men aged 70-89 years without diabetes is shown in Fig. 1. The median (interquartile range) for HOMA2-IR was 0.969 (0.660-1.451).

\section{Characteristics of study participants accor- ding to quintiles of HOMA2-IR}

The anthropometric, clinical and biochemical characteristics of this cohort of men are shown in Table 1. Data are presented for each quintile of HOMA2-IR values. From the lowest to highest quintiles of HOMA2-IR, increasing insulin resistance was associated with higher BMI, waist circumference, blood pressure and TGs and with lower age, HDL cholesterol and total cholesterol. Total testosterone, calculated free testosterone, SHBG and LH decreased across quintiles of HOMA2-IR.

\section{Correlations between sex hormones and HOMA2-IR values}

Total testosterone and SHBG correlated inversely with $\log$ HOMA2-IR $(r=-0.27$ and -0.24 respectively, $P<0.001$ for both; Table 2, Fig. 2A and B).

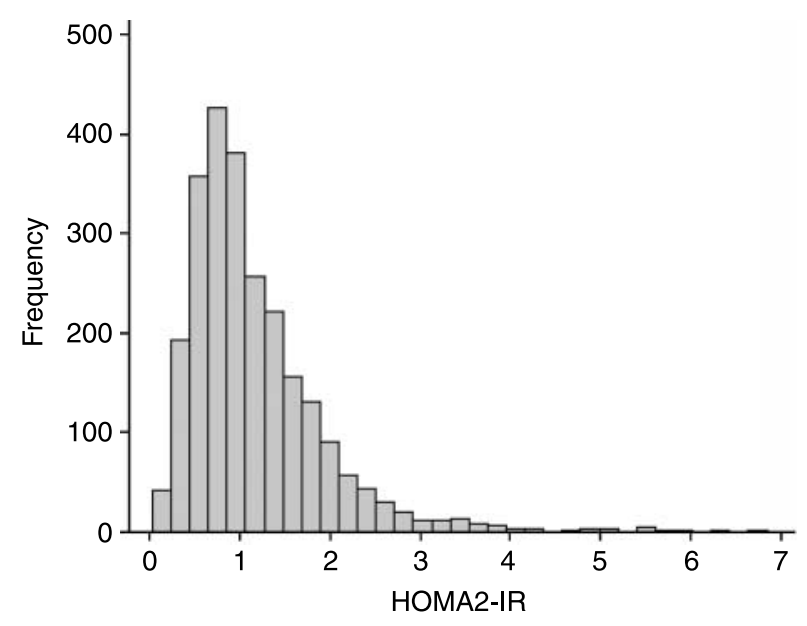

Figure 1 Distribution of HOMA2-IR values in 2470 non-diabetic community-dwelling men aged $70-89$ years.
Free testosterone also correlated inversely with log HOMA2-IR ( $r=-0.14, P<0.001$; Fig. 2C). There was a weaker inverse correlation between log LH and log HOMA2-IR. Waist circumference and BMI were positively correlated with log HOMA2-IR (Fig. 2D). Log TG was positively and HDL was inversely correlated with $\log$ HOMA2-IR. It is possible that several men might have received testosterone supplementation without disclosing this information, resulting in supraphysiological levels of total or free testosterone (Fig. 2A and $\mathrm{C}$ ). Exclusion of outliers from the analysis (men with total or free testosterone or SHBG in the lowest $1 \%$ or highest $1 \%$ of values, $n=109$ ) did not appreciably alter the results.

\section{Multivariate analyses}

Univariate and multivariate analyses were performed to examine the associations between variables and log HOMA2-IR. Medical comorbidity, smoking and blood pressure were associated with log HOMA2-IR in univariate models, but not after adjusting for other covariates. The final multivariate model adjusted for age, BMI, waist circumference, HDL, TG and hormone levels. In the adjusted model, lower total testosterone was independently associated with insulin resistance (log HOMA2-IR; Table 3A). SHBG was not independently associated with HOMA2-IR (Table 3A), nor was LH (data not shown). In the multivariate model, a decrease in total testosterone level of 1 S.D. $(5.6 \mathrm{nmol} / \mathrm{l})$ was associated with $28 \%$ higher odds of having HOMA2-IR in the highest quintile of values (Table 3B). Lower free testosterone was also associated with insulin resistance (log HOMA2-IR as a continuous variable, Table 3C, or highest quintile of values Table 3D). Exclusion of outliers from the analysis (men with total or free testosterone or SHBG in the lowest $1 \%$ or highest $1 \%$ of values) did not appreciably alter the results.

\section{Stratification of testosterone concentrations}

After adjusting for age, BMI, waist circumference, HDL and TG levels, serum total testosterone $<8 \mathrm{nmol} / \mathrm{l}$ was associated with HOMA2-IR in the highest quintile $(n=99$, odds ratio (OR) $1.67,95 \%$ confidence interval (CI) $1.02-2.73, P=0.04)$ compared with total testosterone $\geq 8 \mathrm{nmol} / \mathrm{l}$. In multivariate analysis, total testosterone $\geq 8$ and $<15 \mathrm{nmol} / \mathrm{l}$ was also associated with HOMA2-IR in the highest quintile of values $(n=1033$, OR 1.29, 95\% CI 1.03-1.63, $P=0.008$ ) compared with total testosterone $\geq 15 \mathrm{nmol} / \mathrm{l}$.

\section{Discussion}

In this analysis of 2470 non-diabetic communitydwelling men aged 70 years and above, lower total and free testosterone were independently associated with higher insulin resistance. In contrast, SHBG was 
Table 1 Characteristics of 2470 non-diabetic older men by quintiles of HOMA2-IR. Data are mean \pm S.D., or median (interquartile range).

\begin{tabular}{|c|c|c|c|c|c|c|}
\hline \multirow[b]{2}{*}{ HOMA2-IR } & \multicolumn{5}{|c|}{ HOMA2-IR quintile } & \multirow[b]{2}{*}{$\begin{array}{c}P \text { value } \\
\text { for trend }\end{array}$} \\
\hline & $\begin{array}{l}1(n=493) \\
0.03-0.592\end{array}$ & $\begin{array}{l}2(n=494) \\
0.593-0.841\end{array}$ & $\begin{array}{l}3(n=492) \\
0.842-1.121\end{array}$ & $\begin{array}{l}4(n=497) \\
1.122-1.584\end{array}$ & $\begin{array}{l}5(n=494) \\
1.587-6.849\end{array}$ & \\
\hline Age (years) & $76.8(74.4-79.3)$ & $76.9(74.1-79.5)$ & $76.3(74.0-79.1)$ & $76.2(74.2-79.2)$ & $75.8(74.1-78.6)$ & 0.001 \\
\hline $\mathrm{BMI}\left(\mathrm{kg} / \mathrm{m}^{2}\right)$ & $24.0+2.9$ & $25.2+2.8$ & $26.1+3.0$ & $27.2+3.3$ & $28.7+3.6$ & $<0.001$ \\
\hline Waist (cm) & $91.7 \pm 7.9$ & $95.0 \pm 7.8$ & $97.4 \pm 8.1$ & $101.0 \pm 8.4$ & $105.2 \pm 9.3$ & $<0.001$ \\
\hline WHR & $0.93 \pm 0.06$ & $0.95 \pm 0.06$ & $0.96 \pm 0.06$ & $0.98 \pm 0.08$ & $1.00 \pm 0.06$ & $<0.001$ \\
\hline Systolic BP (mmHg) & $144.6 \pm 19.3$ & $146.3 \pm 19.6$ & $147.6 \pm 19.9$ & $147.5 \pm 20.0$ & $148.8 \pm 19.8$ & 0.001 \\
\hline Diastolic BP $(\mathrm{mmHg})$ & $72.6 \pm 10.2$ & $74.1 \pm 10.3$ & $75.2 \pm 9.8$ & $75.1 \pm 9.8$ & $75.9 \pm 9.9$ & $<0.001$ \\
\hline Glucose $(\mathrm{mmol} / \mathrm{l})$ & $5.1 \pm 0.5$ & $5.3 \pm 0.5$ & $5.4 \pm 0.5$ & $5.5 \pm 0.5$ & $5.8 \pm 1.0$ & $<0.001$ \\
\hline Insulin (mU//) & $3.0(2.4-3.5)$ & $4.8(4.4-5.2)$ & $6.4(6.0-6.9)$ & $8.8(8.1-9.6)$ & $13.4(11.8-16.4)$ & $<0.001$ \\
\hline $\mathrm{TG}(\mathrm{mmol} / \mathrm{l})$ & $0.9(0.6-1.1)$ & $1.0(0.7-1.3)$ & $1.1(0.8-1.5)$ & $1.1(0.9-1.6)$ & $1.4(1.1-1.9)$ & $<0.001$ \\
\hline $\mathrm{HDL}(\mathrm{mmol} / \mathrm{l})$ & $1.6(1.4-1.8)$ & $1.4(1.3-1.7)$ & $1.4(1.2-1.6)$ & $1.3(1.1-1.5)$ & $1.2(1.1-1.5)$ & $<0.001$ \\
\hline LDL (mmol/l) & $2.9(2.4-3.5)$ & $3.1(2.4-3.6)$ & $3.0(2.4-3.6)$ & $3.0(2.4-3.5)$ & $2.8(2.3-3.4)$ & 0.028 \\
\hline Total cholesterol $(\mathrm{mmol} / \mathrm{l})$ & $5.1(4.4-5.6)$ & $5.0(4.4-5.6)$ & $5.0(4.4-5.7)$ & $4.9(4.3-5.5)$ & $4.9(4.2-5.5)$ & 0.009 \\
\hline Total testosterone $(\mathrm{nmol} / \mathrm{l})$ & $18.2 \pm 6.5$ & $16.8 \pm 5.3$ & $15.9 \pm 5.2$ & $15.4 \pm 5.0$ & $14.0 \pm 5.2$ & $<0.001$ \\
\hline Free testosterone $(\mathrm{pmol} / \mathrm{l})$ & $302.8 \pm 103.8$ & $295.0 \pm 88.1$ & $287.1 \pm 83.1$ & $283.7 \pm 83.1$ & $265.5 \pm 88.7$ & $<0.001$ \\
\hline SHBG $(\mathrm{nmol} / \mathrm{l})$ & $49.5 \pm 18.1$ & $45.3 \pm 16.5$ & $42.3 \pm 14.9$ & $41.1 \pm 15.2$ & $38.9 \pm 17.0$ & $<0.001$ \\
\hline LH (IU/I) & $4.6(3.1-6.8)$ & $4.2(2.9-6.4)$ & $4.1(3.0-6.0)$ & $4.1(2.9-6.3)$ & $4.1(2.8-6.1)$ & 0.005 \\
\hline
\end{tabular}

aBased on Cuzick's non-parametric test for trend.

not associated with HOMA2-IR after adjustment for potential confounders. Of note, while measures of central adiposity such as BMI and waist circumference are associated with higher insulin resistance, our data show that the association between total testosterone and HOMA2-IR is independent of these covariates as well as of SHBG. This is consistent with our observation of a significant independent association between free testosterone and HOMA2-IR.

Our findings are consistent with previous smaller studies that included middle-aged and older men. Simon et al. (25) found that total testosterone levels decreased with increasing insulin levels in 1297 healthy Caucasian men aged 20-60 years. This decrease was reduced but remained graded and significant after adjusting for age, BMI and skinfold thickness. Tibblin et al. (6) studied 651 men at 67 years of age and found that total and free testosterone and SHBG were negatively correlated with fasting insulin levels. Oh et al. (26) conducted a longitudinal assessment of 294 men aged 55-89 years in the Rancho Bernardo Study. In age-adjusted and multivariate analyses, total testosterone was negatively correlated with insulin resistance in men.

However, our findings are contrary to the results from a recent study of non-diabetic middle-aged men in which the association between total testosterone and insulin sensitivity was apparently mediated by SHBG (27). In that study, Rajala et al. reported a cross-sectional analysis of 438 men aged around 55 years, finding that insulin sensitivity (measured with the quantitative insulin sensitivity check index, QUICKI) was positively correlated with SHBG and total testosterone. However, adjustment for SHBG rendered the correlation between QUICKI and total testosterone non-significant, while the correlation between QUICKI and SHBG remained significant after adjustment for multiple covariates including BMI and total testosterone (27). Their conclusion was that the association between total testosterone and insulin sensitivity was mediated by SHBG. Our observations are also in contrast with those of Tsai et al. (4), who studied 221 non-diabetic middleaged men aged 45-65 years and found that SHBG was independently associated with insulin resistance even after controlling for body fat, whereas the significant inverse associations between bioavailable and free testosterone with HOMA-IR were not independent of body fat (4). In our study, the association between lower testosterone level and insulin resistance was independent of SHBG (which was not associated with HOMA2-IR) and measures of adiposity. It is not clear why our results differ from those of Tsai et al. and Rajala et al. Our study was rather larger than those investigations and therefore would have had higher power to detect the subtle association between testosterone and insulin resistance after adjustment for confounders. Alternatively, the relationship between SHBG and insulin resistance may differ in older compared with middle-aged men. In older men, circulating levels of SHBG are higher but there is no independent association of SHBG with insulin resistance.

We have previously reported that lower SHBG and testosterone levels are independently associated with metabolic syndrome in this cohort of men, with SHBG being the more strongly associated (28). However, when it comes specifically to insulin sensitivity in older men, SHBG might possess less utility as a marker, since in the present study it was not associated with insulin resistance. One possible explanation for this observation could be that higher BMI is correlated with higher circulating insulin levels, and insulin suppresses hepatic synthesis of SHBG $(12,29)$. Therefore, BMI, SHBG and insulin resistance may be interrelated 


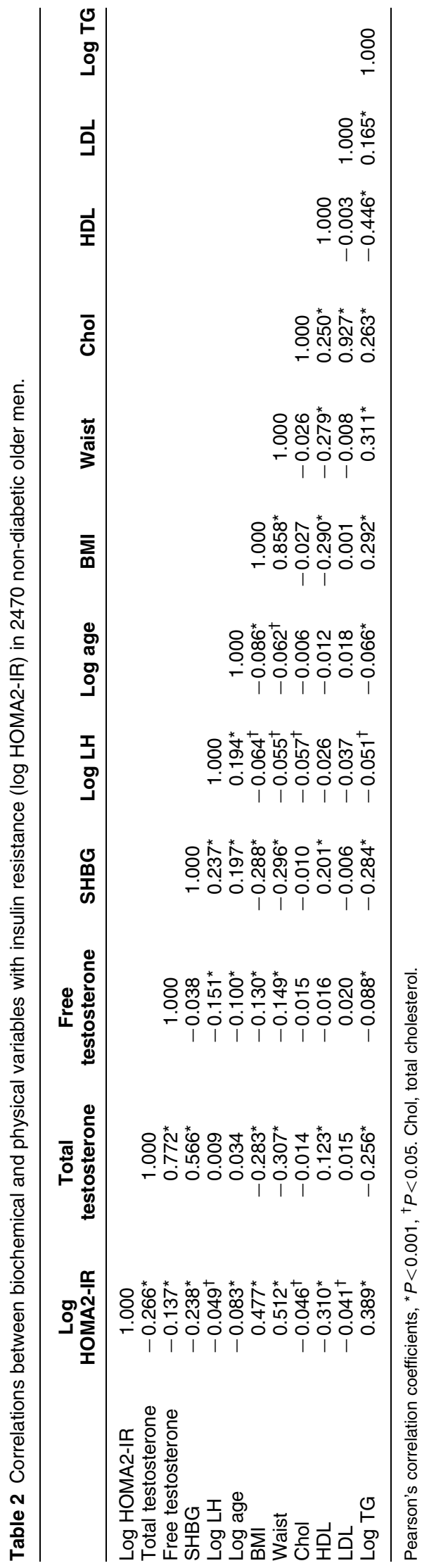

rather than independently associated in older men. The absence of an independent association between SHBG and insulin sensitivity suggests that the agerelated rise in SHBG may not be protective against insulin resistance in older men.

Central adiposity is a recognised predictor of lower testosterone levels (30), and in our study, waist circumference showed the strongest association with insulin resistance. However, after adjusting for BMI and waist circumference, a significant and independent association between lower testosterone and insulin resistance remained, which was moderate in magnitude. Furthermore, a total testosterone level $<8 \mathrm{nmol} / \mathrm{l}$ was associated with higher HOMA2-IR as was total testosterone $\geq 8$ and $<15 \mathrm{nmol} / \mathrm{l}$. Therefore, the association between lower testosterone and reduced insulin sensitivity is independent of measures of central adiposity and is not confined to men with unequivocally low testosterone levels, extending to men with testosterone levels in the low normal range.

The strengths of this study are the size of the cohort; the fact that its members were community-dwelling rather than selected on the basis of some other health condition, and its involvement of men older than 70 years. Fasting blood samples were collected in the morning from each of our participants to minimise potential effects of circadian variation on testosterone concentrations. Limitations of this study include the cross-sectional nature of the analysis and the use of a single blood sample. Blood sampling at a single time point offers a reasonable estimate of usual testosterone levels (31), and the scope of the study did not extend to repeated blood sampling or to assay of other hormones such as oestradiol. Data derived via measurement of total testosterone by immunoassay should not be extrapolated widely without considering the potential for different testosterone immunoassays to give varying results (32). Also, calculation of free testosterone may not correlate exactly with directly measured circulating free testosterone (33). However, these methods have been used extensively in large studies where measurement of total testosterone by mass spectrometry and free testosterone by equilibrium dialysis may be impractical. Additionally, insulin resistance was estimated using HOMA2-IR. While this method has limitations, it correlates with assessment of insulin sensitivity by euglycaemic clamp (for review, please refer to (24)). As we studied men without diabetes from whom fasting blood samples were obtained, the calculation of HOMA2-IR was not confounded by postprandial status or use of sulphonylurea drugs or insulin.

Although this is a cross-sectional analysis from which causality cannot be inferred, our findings are consistent with other published data indicating a role for testosterone in the regulation of body composition and insulin sensitivity. Compared with placebo, testosterone supplementation in non-obese men with baseline total testosterone concentrations $<15 \mathrm{nmol} / \mathrm{l}$ increased fat 

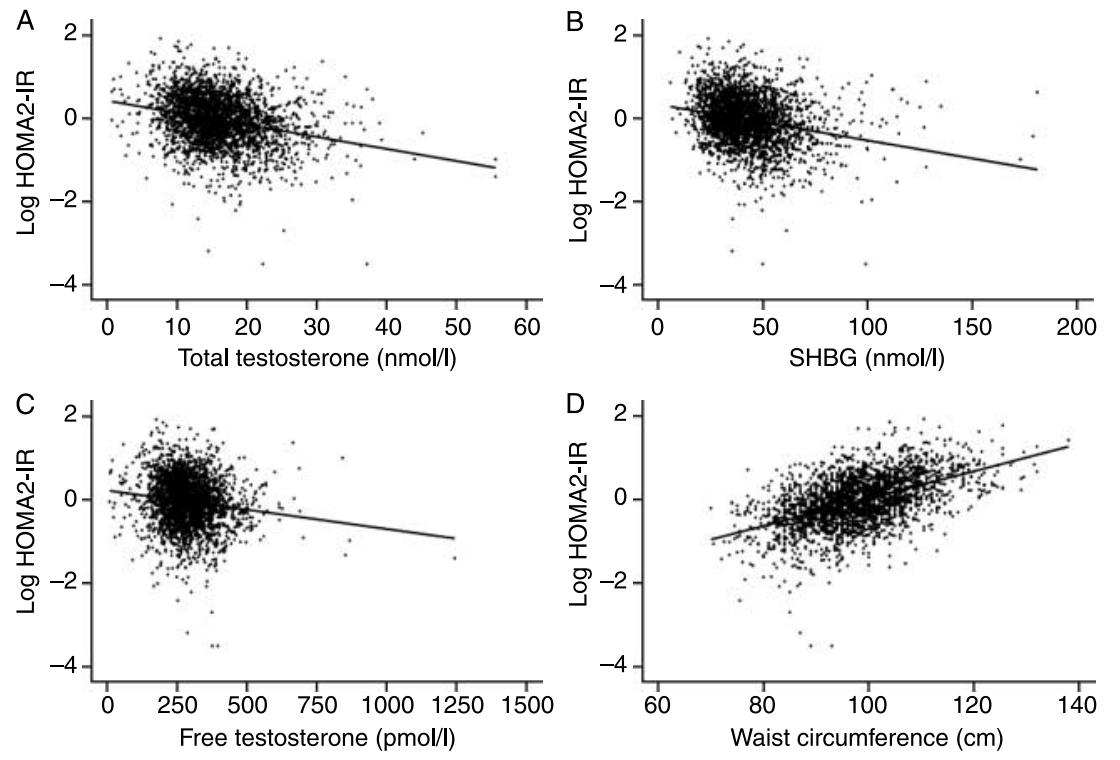

Figure 2 Correlations between log HOMA2-IR with (A) total testosterone, (B) SHBG, (C) free testosterone and (D) waist circumference in non-diabetic older men.

free mass and decreased accumulation of visceral fat (34). In a study of 60 men aged 60.5 years, testosterone levels correlated with insulin sensitivity measured with hyperinsulinemic-euglycemic clamp studies, maximal aerobic capacity $\left(\mathrm{VO}_{2 \max }\right)$ and muscle expression of genes involved in oxidative phosphorylation, suggesting a relationship between decreased testosterone and impaired mitochondrial function (5). The relationship between testosterone and insulin resistance may be to some extent bidirectional, as under experimental conditions increasing insulin resistance is associated with decreased Leydig cell secretion of testosterone (35). Thus, men with type 2 diabetes commonly exhibit low testosterone levels (36), and in hypogonadal men with type 2 diabetes, testosterone treatment reduces insulin resistance and improves glycaemic control (37). Androgen deprivation therapy for men with prostate cancer is associated with adverse metabolic changes including the development of hyperinsulinemia (38), and shortterm withdrawal of testosterone therapy in hypogonadal men aged 40.8 years (range 29-67 years) increased insulin resistance (39). However, a recent interventional study in 55 men aged 63-72 years did not demonstrate an effect of testosterone patch therapy on insulin secretion or postprandial glucose metabolism after an interval of 2 years (40). Therefore, additional interventional studies are needed to clarify potential benefits and risks of manipulating testosterone levels in men who are predisposed to insulin resistance, specifically considering men with testosterone levels in

Table 3 Multivariate analysis of factors associated with insulin resistance (log HOMA2-IR). (A) Linear regression with log HOMA2-IR as a continuous variable and $(B)$ logistic regression showing change in odds ratio of having HOMA2-IR in the highest quintile of values for a 1 s.D. decrease in age, body mass index (BMI), total testosterone, sex hormone-binding globulin (SHBG), waist circumference, high-density lipoprotein (HDL) or triglyceride (TG). (C) Linear regression and (D) logistic regression with free testosterone instead of total testosterone and SHBG in the adjusted models.

\begin{tabular}{|c|c|c|c|c|c|c|}
\hline & Coefficient & $\begin{array}{l}95 \% \text { Confidence } \\
\text { interval }\end{array}$ & $P$ value & $\begin{array}{l}\text { Odds } \\
\text { ratio }\end{array}$ & $\begin{array}{l}95 \% \text { Confidence } \\
\text { interval }\end{array}$ & $P$ value \\
\hline & & (A) Linear regression & & & (B) Logistic regression & \\
\hline Age & 0.028 & $0.008,0.049$ & 0.006 & 1.15 & $1.02,1.29$ & 0.023 \\
\hline $\mathrm{BMI}$ & -0.061 & $-0.100,-0.022$ & 0.002 & 0.82 & $0.67,1.01$ & 0.069 \\
\hline Waist circumference & -0.195 & $-0.234,-0.156$ & $<0.001$ & 0.48 & $0.39,0.59$ & $<0.001$ \\
\hline Total testosterone & 0.054 & $0.030,0.079$ & $<0.001$ & 1.28 & $1.10,1.48$ & 0.001 \\
\hline SHBG & -0.009 & $-0.034,0.16$ & 0.489 & 0.87 & $0.75,0.99$ & 0.043 \\
\hline $\mathrm{HDL}$ & 0.070 & $0.048,0.093$ & $<0.001$ & 1.20 & $1.05,1.38$ & 0.008 \\
\hline TG & -0.105 & $\begin{array}{l}-0.128,-0.083 \\
\text { (C) Linear regression }\end{array}$ & $<0.001$ & 0.69 & $\begin{array}{c}0.62,0.77 \\
\text { (D) Logistic regression }\end{array}$ & $<0.001$ \\
\hline Age & 0.032 & $0.012,0.052$ & 0.002 & 1.14 & $1.02,1.28$ & 0.025 \\
\hline $\mathrm{BMI}$ & -0.062 & $-0.101,-0.023$ & 0.002 & 0.83 & $0.67,1.02$ & 0.074 \\
\hline Waist circumference & -0.200 & $-0.239,-0.161$ & $<0.001$ & 0.48 & $0.39,0.59$ & $<0.001$ \\
\hline Free testosterone & 0.040 & $0.020,0.061$ & $<0.001$ & 1.21 & $1.07,1.37$ & 0.002 \\
\hline $\mathrm{HDL}$ & 0.073 & $0.050,0.095$ & $<0.001$ & 1.20 & $1.05,1.38$ & 0.007 \\
\hline TG & -0.110 & $-0.132,-0.087$ & $<0.001$ & 0.69 & $0.62,0.77$ & $<0.001$ \\
\hline
\end{tabular}


the low-normal range. These will need to be viewed in the context of interventions that focus directly on weight reduction, or encourage engagement in healthy lifestyle behaviours (41). At present, testosterone supplementation should only be considered in men who meet accepted criteria for the diagnosis of androgen deficiency, which include symptoms consistent with hypogonadism and confirmed low early morning testosterone levels (42).

In summary, low testosterone levels are associated with reduced insulin sensitivity in non-diabetic older men, independently of SHBG and measures of central adiposity. Even men with low-normal testosterone levels exhibit reduced insulin sensitivity. Further studies are needed to evaluate potential benefits and risks of testosterone therapy in men at risk of cardiovascular disease.

\section{Declaration of interest}

The authors have no conflicts of interest to declare.

\section{Funding}

Hormone assays were funded by a Clinical Investigator Award to B B Yeap from the Sylvia and Charles Viertel Charitable Foundation, New South Wales, Australia, and by a Research Grant to SAP Chubb from the Fremantle Hospital Medical Research Foundation, Western Australia. The Health In Men Study was funded by Project Grants 279408, 379600, 403963 and 513823 from the National Health and Medical Research Council of Australia (NHMRC). P E Norman is supported by an NHMRC Practitioner Fellowship (458505).

\section{Acknowledgements}

Support from Dr George Koumantakis of Roche Diagnostics Australia for the supply of insulin assay reagents is gratefully acknowledged. The authors thank Tricia Knox and the staff of the Departments of Biochemistry, PathWest, Royal Perth and Fremantle Hospitals, Western Australia for their assistance in performing the hormone assays, Peter Feddema from DPC-BioMediq, Australia for his assistance with sourcing hormone assay kits and reagents and Dr Kieran McCaul, Senior Research Fellow, Centre for Health and Ageing, University of Western Australia for his advice regarding the statistical analyses. We thank the staff and management of Shenton Park Hospital for providing space in which to conduct follow-up clinics. We especially thank all the men and staff who participated in the Western Australian Abdominal Aortic Aneurysm Programme and the Health in Men Study.

\section{References}

1 Bonora E, Kiechl S, Willeit J, Oberhollenzer F, Egger G, Meigs JB, Bonadonna RC \& Muggeo M. Insulin resistance as estimated by homeostasis model assessment predicts incident symptomatic cardiovascular disease in Caucasian subjects from the general population. Diabetes Care 200730 318-324.

2 Saely CH, Aczel S, Marte T, Langer P, Hoefle G \& Drexel H. The metabolic syndrome, insulin resistance, and cardiovascular risk in diabetic and nondiabetic patients. Journal of Clinical Endocrinology and Metabolism 200590 5698-5703.
3 Holmang A \& Bjorntorp P. The effects of testosterone on insulin sensitivity in male rats. Acta Physiologica Scandinavica 1992146 505-510.

4 Tsai EC, Matsumoto AM, Fujimoto WY \& Boyko EJ. Association of bioavailable, free, and total testosterone with insulin resistance: influence of sex hormone-binding globulin and body fat. Diabetes Care 200427 861-868.

5 Pitteloud N, Mootha VK, Dwyer AA, Hardin M, Lee H, Eriksson K-F, Tripathy D, Yialamas M, Groop L, Elahi D \& Hayes FJ. Relationship between testosterone levels, insulin sensitivity, and mitochondrial function in men. Diabetes Care 200528 1636-1642.

6 Tibblin G, Adlerberth A, Lindstedt G \& Bjorntorp P. The pituitarygonadal axis and health in elderly men. Diabetes $1996 \mathbf{4 5}$ 1605-1609.

7 Laaksonen DE, Niskanen L, Punnonen K, Nyyssonen K, Tuomainen T-P, Valkonen V-P, Salonen R \& Salonen JT. Testosterone and sex hormone-binding globulin predict the metabolic syndrome and diabetes in middle-aged men. Diabetes Care 200427 1036-1041.

8 Kupelian V, Page ST, Araujo AB, Travison TG, Bremner WJ \& McKinlay JB. Low sex hormone-binding globulin, total testosterone, and symptomatic androgen deficiency are associated with development of the metabolic syndrome in nonobese men. Journal of Clinical Endocrinology and Metabolism 200691 843-850.

9 Khaw K-T, Dowsett M, Folkerd E, Bingham S, Wareham N, Luben R, Welch A \& Day N. Endogenous testosterone and mortality due to all causes, cardiovascular disease, and cancer in men. Circulation 2007116 2694-2701.

10 Laughlin GA, Barrett-Connor E \& Bergstrom J. Low serum testosterone and mortality in older men. Journal of Clinical Endocrinology and Metabolism 200893 68-75.

11 Kaufman JM \& Vermeulen A. The decline of androgen levels in elderly men and its clinical and therapeutic implications. Endocrine Reviews 200526 833-876.

12 Osuna JA, Gomez-Perez R, Arata-Bellabarba G \& Villaroel V. Relationship between BMI, total testosterone, sex hormonebinding-globulin, leptin, insulin and insulin resistance in obese men. Archives of Andrology 200652 355-361.

13 Kalme T, Seppälä M, Qiao Q, Koistinen R, Nissinen A, Harrela M, Loukovaara M, Leinonen P \& Tuomilehto J. Sex hormone-binding globulin and insulin-like growth factor-binding protein-1 as indicators of metabolic syndrome, cardiovascular risk, and mortality in elderly men. Journal of Clinical Endocrinology and Metabolism 200590 1550-1556.

14 Harman SM, Metter EJ, Tobin JD, Pearson J \& Blackman MR. Longitudinal effects of aging on serum total and free testosterone levels in healthy men. Journal of Clinical Endocrinology and Metabolism 200186 724-731.

15 Feldman HA, Longcope C, Derby CA, Johannes CB, Araujo AB, Coviello AD, Bremner WJ \& McKinlay JB. Age trends in the level of serum testosterone and other hormones in middle-aged men: longitudinal results from the Massachusetts Male Aging Study. Journal of Clinical Endocrinology and Metabolism $2002 \mathbf{8 7}$ 589-598.

16 Orwoll E, Lambert LC, Marshall LM, Phipps K, Blank J, BarrettConnor E, Cauley J, Ensrud K \& Cummings S. Testosterone and estradiol in older men. Journal of Clinical Endocrinology and Metabolism 200691 1336-1344.

17 Yeap BB, Almeida OP, Hyde Z, Norman PE, Chubb SAP, Jamrozik K \& Flicker L. In men older than 70 years, total testosterone remains stable while free testosterone declines with age. The Health in Men Study. European Journal of Endocrinology 2007156 585-594.

18 Lapauw B, Goemaere S, Zmierczak H, Van Pottelbergh I, Mahmoud A, Taes Y, De Bacquer D, Vansteelandt D \& Kaufman JM. The decline of serum testosterone levels in community-dwelling men over 70 years of age: descriptive data and predictors of longitudinal changes. European Journal of Endocrinology 2008159 459-468.

19 Norman PE, Flicker L, Almeida OP, Hankey GJ, Hyde Z \& Jamrozik K. Cohort profile: the Health in Men Study (HIMS). International Journal of Epidemiology 200938 48-52. 
20 Charlson ME, Pompei P, Ales KL \& MacKenzie CR. A new method of classifying prognostic comorbidity in longitudinal studies: development and validation. Journal of Chronic Diseases $1987 \mathbf{4 0}$ 373-383.

21 Holman CD, Bass AJ, Rouse IL \& Hobbs MS. Population-based linkage of health records in Western Australia: development of a health services research linked database. Australian and New Zealand Journal of Public Health 199923 453-459.

22 Quan H, Sundararajan V, Halfon P, Fong A, Burnand B, Luthi JC, Saunders LD, Beck CA, Feasby TE \& Ghali WA. Coding algorithms for defining comorbidities in ICD-9-CM and ICD-10 administrative data. Medical Care 200543 1130-1139.

23 Vermeulen A, Verdonck L \& Kaufman JM. A critical evaluation of simple methods for the estimation of free testosterone in serum. Journal of Clinical Endocrinology and Metabolism $1999 \mathbf{8 4}$ 3666-3672.

24 Wallace TM, Levy JC \& Matthews DR. Use and abuse of HOMA modelling. Diabetes Care 200427 1487-1495.

25 Simon D, Preziosi P, Barrett-Connor E, Roger M, Saint-Paul M, Nahoul K \& Papoz L. Interrelation between plasma testosterone and plasma insulin in healthy adult men: the Telecom Study. Diabetologia 199235 173-177.

26 Oh J-Y, Barrett-Connor E, Wedick NM \& Wingard DL. Endogenous sex hormones and the development of type 2 diabetes in older men and women: the Rancho Bernardo Study. Diabetes Care 200225 $55-60$.

27 Rajala UM, Keinanen-Kiukaanniemi SM, Hirsso PK, Jokelainen JJ, Laakso MA, Hiltunen LA, Ruokonen AO, Harkonen PK \& Timonen MJ. Associations of total testosterone and sex hormone-binding globulin levels with insulin sensitivity in middle-aged Finnish men. Diabetes Care 200730 e13.

28 Chubb SAP, Hyde Z, Almeida OP, Flicker L, Norman PE, Jamrozik K, Hankey GJ \& Yeap BB. Lower sex hormone binding globulin is more strongly associated with metabolic syndrome than lower total testosterone in older men. The Health in Men Study. European Journal of Endocrinology 2008158 785-792.

29 Yki-Jarvinen H, Makimattila S, Utriainen T \& Rutanen EM. Portal insulin concentrations rather than insulin sensitivity regulate serum sex hormone-binding globulin and insulin-like growth factor binding protein 1 in vivo. Journal of Clinical Endocrinology and Metabolism 199580 3227-3232.

30 Wu FC, Tajar A, Pye SR, Silman AJ, Finn JD, O’Neill TW, Bartfai G, Casanueva F, Forti G, Giwercman A, Huhtaniemi IT, Kula K, Punab M, Boonen S \& Vanderschueren D. Hypothalamicpituitary-testicular axis disruptions in older men are differentially linked to age and modifiable risk factors: the European Male Aging Study. Journal of Clinical Endocrinology and Metabolism 200893 2737-2745.

31 Vermeulen A \& Verdonck G. Representativeness of a single point plasma testosterone level for the long term hormonal milieu in men. Journal of Clinical Endocrinology and Metabolism $1992 \mathbf{7 4}$ 939-942.
32 Rosner W, Auchus RJ, Azziz R, Sluss PM \& Raff H. Utility, limitations, and pitfalls in measuring testosterone: an Endocrine Society Position Statement. Journal of Clinical Endocrinology and Metabolism 200792 405-413.

33 Ly LP \& Handelsman DJ. Empirical estimation of free testosterone from testosterone and sex hormone-binding globulin immunoassays. European Journal of Endocrinology 2005152 471-478.

34 Allan CA, Strauss BJG, Burger HG, Forbes EA \& McLachlan RI. Testosterone therapy prevents gain in visceral adipose tissue and loss of skeletal muscle in nonobese aging men. Journal of Clinical Endocrinology and Metabolism 200893 139-146.

35 Pitteloud N, Hardin M, Dwyer AA, Valassi E, Yialamas M, Elahi D \& Hayes FJ. Increasing insulin resistance is associated with a decrease in Leydig cell testosterone secretion in men. Journal of Clinical Endocrinology and Metabolism 200590 2636-2641.

36 Grossmann M, Thomas MC, Panagiotopoulos S, Sharpe K, Macisaac RJ, Clarke S, Zajac JD \& Jerums G. Low testosterone levels are common and associated with insulin resistance in men with diabetes. Journal of Clinical Endocrinology and Metabolism 200893 1834-1840.

37 Kapoor D, Goodwin E, Channer KS \& Jones TH. Testosterone replacement therapy improves insulin resistance, glycaemic control, visceral adiposity and hypercholesterolaemia in hypogonadal men with type 2 diabetes. European Journal of Endocrinology 2006154 899-906.

38 Shahani S, Braga-Basaria M \& Basaria S. Androgen deprivation therapy in prostate cancer and metabolic risk for atherosclerosis. Journal of Clinical Endocrinology and Metabolism 200893 2042-2049.

39 Yialamas MA, Dwyer AA, Hanley E, Lee H, Pitteloud N \& Hayes FJ. Acute sex steroid withdrawal reduces insulin sensitivity in healthy men with idiopathic hypogonadotrophic hypogonadism. Journal of Clinical Endocrinology and Metabolism 200792 4254-4259.

40 Basu R, Dalla Man C, Campioni M, Basu A, Nair SK, Jensen MD, Khosla S, Klee G, Toffolo G, Cobelli C \& Rizza RA. Effect of 2 years of testosterone replacement on insulin secretion, insulin action, glucose effectiveness, hepatic insulin clearance, and postprandial glucose turnover in elderly men. Diabetes Care 200730 1972-1978.

41 Yeap BB, Almeida OP, Hyde Z, Norman PE, Chubb SAP, Jamrozik K, Hankey GJ \& Flicker L. Healthier lifestyle predicts higher circulating testosterone in older men. The Health in Men Study. Clinical Endocrinology $200970455-463$.

42 Wang C, Nieschlag E, Swerdloff R, Behre HM, Hellstrom WJ, Gooren LJ, Kaufman JM, Legros J-J, Lunenfeld B, Morales A, Morley JE, Schulman C, Thompson IM, Weidner W \& Wu FCW. Investigation, treatment and monitoring of late-onset hypogonadism in males: ISA, ISSAM, EAU, EAA and ASA recommendations. European Journal of Endocrinology 2008159 507-514.

Received 26 June 2009

Accepted 4 August 2009 